\title{
Use of PCR-restriction fragment length polymorphism analysis for identification of yeast species isolated from bovine intramammary infection
}

\author{
M. E. Fadda, ${ }^{* 1}$ M. B. Pisano, ${ }^{*}$ L. Scaccabarozzi, $†$ V. Mossa, ${ }^{*}$ M. Deplano, ${ }^{*}$ P. Moroni, $\ddagger$ M. Liciardi,§ \\ and S. Cosentino* \\ *Università degli Studi di Cagliari, Dipartimento di Sanità Pubblica, Medicina Clinica e Molecolare, Cittadella Universitaria, 09124 Cagliari, Italy \\ †Università degli Studi di Milano, Dipartimento di Scienze Veterinarie per la Salute, la Produzione Animale e la Sicurezza Alimentare, \\ 20133 Milan, Italy \\ $\ddagger$ Animal Health Diagnostic Center, Quality Milk Production Service, Cornell University, Ithaca, NY 14853 \\ §Istituto Zooprofilattico Sperimentale della Sardegna, Dipartimento di Cagliari, 09030 Cagliari, Italy
}

\begin{abstract}
This study reports a rapid PCR-based technique using a one-enzyme RFLP for discrimination of yeasts isolated from bovine clinical and subclinical mastitis milk samples. We analyzed a total of 1,486 milk samples collected over $1 \mathrm{yr}$ in south Sardinia and northern Italy, and 142 yeast strains were preliminarily grouped based on their cultural morphology and physiological characteristics. Assimilation tests were conducted using the identification kit API ID 32C and APILAB Plus software (bioMérieux, Marcy l'Etoile, France). For PCR-RFLP analysis, the 18S-ITS1-5.8S ribosomal(r) DNA region was amplified and then digested with HaeIII, and dendrogram analysis of RFLP fragments was carried out. Furthermore, within each of the groups identified by the API or PCR-RFLP methods, the identification of isolates was confirmed by sequencing of the D1/D2 region using an ABI Prism 310 automatic sequencer (Applied Biosystems, Foster City, CA). The combined phenotypic and molecular approach enabled the identification of 17 yeast species belonging to the genera Candida (47.9\%), Cryptococcus (21.1\%), Trichosporon (19.7\%), Geotrichum (7.1\%), and Rhodotorula (4.2\%). All Candida species were correctly identified by the API test and their identification confirmed by sequencing. All strains identified with the API system as Geotrichum candidum, Cryptococcus uniguttulatus, and Rhodotorula glutinis also produced characteristic restriction patterns and were confirmed as Galactomyces geotrichum (a teleomorph of G. candidum), Filobasidium uniguttulatum (teleomorph of Crypt. uniguttulatus), and $R$. glutinis, respectively, by D1/D2 rDNA sequencing. With regard to the genus Trichosporon, preliminary identification by API was problematic, whereas the
\end{abstract}

Received May 6, 2013.

Accepted August 16, 2013.

${ }^{1}$ Corresponding author: mefadda@unica.it
RFLP technique used in this study gave characteristic restriction profiles for each species. Moreover, sequencing of the D1/D2 region allowed not only successful identification of Trichosporon gracile where API could not, but also correct identification of misidentified isolates. In conclusion, the 18S-ITS1-5.8S region appears to be useful in detecting genetic variability among yeast species, which is valuable for taxonomic purposes and for species identification. We have established an RFLP database for yeast species identified in milk samples using the software GelCompar II and the RFLP database constitutes an initial method for veterinary yeast identification.

Key words: yeasts, PCR-RFLP, bovine milk, molecular diagnosis

\section{INTRODUCTION}

Mastitis, inflammation of the mammary gland, is a disease that causes enormous losses to the dairy cattle industry, resulting in reductions in the quantity and quality of the milk (Schukken et al., 2009). Bacterial agents are the major cause, but several other groups of microorganisms, including yeasts, fungi, and algae such as Prototheca, have become more frequent (Möller et al., 2007; Seker, 2010). Although yeasts are considered opportunistic pathogens, they have been associated with IMI in dairy cattle, commonly related to treatment directed against other pathogens using contaminated syringes, cannulas, or contaminated antibiotic preparations (Spanamberg et al., 2008; Scaccabarozzi et al., 2011). The most frequently isolated organisms among mastitis-causing yeasts are Candida species, but other yeast genera such as Trichosporon, Cryptococcus, and Geotrichum have also been isolated from clinical cases with low frequencies (Chahota et al., 2001; Spanamberg et al., 2008). The susceptibilities of different species to antifungal agents may be different; therefore, no clear evidence exists of the effectiveness of this therapy (Segundo Zaragoza et al. 2011). 
Traditionally, yeasts are identified by morphological and physiological criteria (Kurtzman and Fell, 2000), but these methods are strongly influenced by culture conditions and can give uncertain results. One of the most successful methods for yeast identification is PCR-RFLP analysis, based on the differentiation of microorganisms by comparison of the restriction patterns obtained by digestion of a chosen target DNA with restriction endonucleases. Here, we report a rapid PCR-based technique, using a one-enzyme RFLP, for discrimination of yeast strains isolated from bovine milk samples with IMI.

\section{MATERIALS AND METHODS}

\section{Sample Collection}

A total of 1,486 milk samples from clinical and subclinical mastitis were collected over 1 yr (from May 2011 to April 2012) in south Sardinia (822) and northern Italy (664). For yeast isolation, the milk samples were cultured on potato dextrose agar supplemented with chloramphenicol (0.01\%; Microbiol, Cagliari, Italy), incubated at $30^{\circ} \mathrm{C}$, and observed daily for growth for up to $1 \mathrm{wk}$.

\section{Identification of Strains}

Colonies appearing as yeast-like in morphology were examined by the Dalmau technique (Odds et al., 1997) for microscopic characteristics. A total of $142(9.5 \%)$ yeast strains (98 in south Sardinia and 44 in northern Italy) were preliminarily grouped based on their culture morphology and physiological characteristics. Assimilation tests were conducted using the identification kit API ID 32C and APILAB Plus software (bioMérieux, Marcy l'Etoile, France).

\section{PCR-RFLP Analysis}

Genomic DNA was extracted as previously described (Fadda et al., 2010). The primers NS1 (5'-GTAGTCATATGCTTGTCTC-3') and ITS2 (5'-GCTGCGTTCTTCATCGATGC-3') were used to amplify most of the $18 \mathrm{~S}$ gene, the internal transcribed spacer (ITS)1 segment, and most of the $5.8 \mathrm{~S}$ gene in ribosomal (r) DNA.

Each reaction mixture contained $5 \mu \mathrm{L}$ of DNA template $(20 \mathrm{ng} / \mu \mathrm{L}), 5 \mu \mathrm{L}$ of $10 \times$ Taq buffer (Eppendorf, Hamburg, Germany), $1 \mu \mathrm{L}$ of $50 \mathrm{mM} \mathrm{MgCl}$ (Eppendorf), $1 \mu \mathrm{L}$ of $10 \mathrm{mM}$ deoxynucleotide triphosphate (dNTP) mix (Eppendorf), $2.5 \mu \mathrm{L}$ each of $10 \mu M$ primers (NS1 and ITS2 (Sigma, St. Louis, MO), $0.5 \mu \mathrm{L}$ of $5 \mathrm{U} / \mu \mathrm{L}$ Taq DNA polymerase (Eppendorf) in 50 $\mu \mathrm{L}$ of final volume. All amplifications were performed in a Mastercycler gradient 5331 (Eppendorf) under the following conditions: initial denaturation of $95^{\circ} \mathrm{C}$ for 3 min followed by 35 cycles of $60 \mathrm{~s}$ at $95^{\circ} \mathrm{C}, 60 \mathrm{~s}$ at $55^{\circ} \mathrm{C}$, and $90 \mathrm{~s}$ at $72^{\circ} \mathrm{C}$, and a final extension step of 5 min at $72^{\circ} \mathrm{C}$. A $6-\mu \mathrm{L}$ aliquot of $\mathrm{PCR}$ product was digested without further purification with $5 \mathrm{U}$ of HaeIII (Sigma) in a final volume of $25 \mu \mathrm{L}$ at $37^{\circ} \mathrm{C}$ for $1.5 \mathrm{~h}$. Amplified products and their restriction fragments were separated on 1.8 and $2.5 \%$ agarose gels, respectively, in $1 \times$ Tris-borate-EDTA buffer. Gels were stained with $0.5 \mu \mathrm{g} / \mathrm{mL}$ ethidium bromide, visualized by using a UV-light transilluminator, and photographed under UV light.

Dendrogram analysis of RFLP fragments was carried out with GelComparII software package (version 6.5; Applied Maths, Kortrijk, Belgium), using the unweighted pair-group method with arithmetic mean (UPGMA) algorithm and Dice similarity coefficient. Restriction fragments shorter than 100 bp were not considered in the analysis.

\section{DNA Sequencing}

The D1/D2 domain of the 26S rRNA gene was amplified with the following primer set: NL1 (5'-GCATATCAATAAGCGGAGGAAAAG-3') and NL4 (5'-GGTCCGTGTTTCAAGACG-3'). Amplification was performed according to the following program sequence: $95^{\circ} \mathrm{C}$ for $4 \mathrm{~min}$, followed by 30 cycles consisting of $94^{\circ} \mathrm{C}$ for $1 \mathrm{~min}, 55^{\circ} \mathrm{C}$ for $2.5 \mathrm{~min}$, and $72^{\circ} \mathrm{C}$ for $2.5 \mathrm{~min}$, with a final extension at $72^{\circ} \mathrm{C}$ for $10 \mathrm{~min}$. The amplified products were purified with PCRExtract Mini Kit (5 Prime, Hamburg, Germany) and were subjected to direct sequencing with an ABI Prism 310 automatic sequencer (Applied Biosystems, Foster City, CA). The results were edited and analyzed by the Basic Local Alignment Search Tool (http://www.ncbi.nlm.nih.gov/ BLAST/). Within each of the species, no more than 2 isolates were analyzed. For the Trichosporon group, the ambiguous results obtained with morphological and biochemical identification led us to perform sequencing of all strains.

\section{RESULTS}

From 1,486 milk samples, we isolated 142 yeast colonies that, based on morphological aspect and assimilation profiles, were identified as indicated in Table 1 . Preliminary classification of 68 Candida strains, by the presence of blastoconidia, pseudohyphae, or both, was confirmed by API system and 8 different species were found at an acceptable to excellent level of identification, according to the APILAB Plus software. 
Table 1. Identification of yeast species by morphological and biochemical tests

\begin{tabular}{llr}
\hline $\begin{array}{l}\text { Genus } \\
\text { (morphological identification) }\end{array}$ & $\begin{array}{c}\text { Strains, } \\
\text { no. }\end{array}$ \\
\hline Candida & Can. famata (acceptable/excellent) & 36 \\
& Can. krusei (excellent/good) & 11 \\
& Can. parapsilosis (excellent/good) & 5 \\
& Can. rugosa (excellent) & 5 \\
Can. utilis (excellent) & 4 \\
Can. inconspicua (good) & 3 \\
Can. sake (excellent) & 3 \\
Cryptococcus curvatus (doubtful/excellent) & 1 \\
Trichosporon & Trichosporon mucoides (low discrimination) & 15 \\
& Cryptococcus laurentii (excellent) & 15 \\
& Trichosporon asahii (good) & 6 \\
Trichosporon inkin (unacceptable profile) & 3 \\
Geotrichum & Unacceptable profile & 2 \\
Cryptococcus & G. candidum (excellent/good) & 2 \\
Pink yeasts & C. uniguttulatus (excellent) & 10 \\
${ }^{1}$ API system (bioMérieux, Marcy l'Etoile, France). & 15 \\
${ }^{2}$ The high variability observed for Cryptococcus strains identification using the API system can be attibuted \\
to the variability of some phenotypic traits among the strains, which is a problem often encountered with \\
phenotypic test-based systems.
\end{tabular}

The genus Trichosporon is phenotypically characterized by the ability to form blastoconidia, true mycelia, and, above all, arthroconidia, asexual spores that disarticulate from true hyphae. Arthroconidia and true mycelia are also present in species of the Geotrichum genus but differences in the ability to hydrolyze urea allowed us to differentiate between the 2 genera. Morphological identification of 10 Geotrichum genera was confirmed by API system with excellent to good conformity as Geotrichum candidum. Preliminary identification of 43 Trichosporon strains, based on arthroconidia presence and positive urease test, was less accurate. In fact, 21 Trichosporon strains were classified as Cryptococcus laurentii (6 strains) and Cryptococcus curvatus (15 strains) with excellent identification and doubtful to excellent identification, respectively (the high variability observed for Cryptococcus strains identification using the API system can be attibuted to the variability of some phenotypic traits among the strains, which is a problem often encountered with phenotypic test-based systems). The identification of only 3 Trichosporon asahii was good, whereas 15 Trichosporon mucoides and 2 Trichosporon inkin strains were identified with low level of discrimination and unacceptable profiles, respectively. Furthermore, 2 strains could not be identified. Budding yeast cells without hyphae and pseudohyphae, preliminarily attributed to Cryptococcus, were identified as Cryptococcus uniguttulatus with a doubtful profile. Pink yeasts included the single species Rhodothorula glutinis.

In an attempt to overcome the ambiguity of the results obtained by taxonomic methods and to develop a rapid and accurate yeast identification technique, a molecular typing method based on PCR-RFLP of the
18S-ITS1-5.8S rDNA region digested with HaeIII was applied in our laboratory to identify yeasts isolated from milk. Furthermore, within each of the groups identified by API or PCR-RFLP method, the identification of isolates was confirmed by sequencing of the D1/D2 region. Table 2 summarizes the results of phenotypic and molecular identification. The small-subunit rRNAcoding DNA with the neighboring ITS region was amplified in all isolates with the exception of 4 strains identified as Candida rugosa, which did not give PCR products under the amplification conditions used. The size of the amplified PCR products ranged from 1.8 to $2.2 \mathrm{kbp}$, not differing sufficiently to distinguish among genera or among species within a genus, but digestion of amplicons by the restriction enzyme HaeIII gave very discriminant results. With the exception of Can. rugosa, the RFLP patterns for all Candida species were completely specific, so none of the species examined was mistaken for another; moreover, D1/D2 sequencing confirmed the API identification at the species level, and homologies from 99 to $100 \%$ were obtained with sequences in GenBank.

All strains identified by the API system as $G$. candidum, Crypto. uniguttulatus, and $R$. glutinis also produced characteristic restriction patterns and were confirmed as Galactomyces geotrichum (teleomorph of G. candidum), Filobasidium uniguttulatum (teleomorph of Crypto. uniguttulatus), and R. glutinis, respectively, by D1/D2 rDNA sequencing, with 99 to $100 \%$ nucleic acid sequence identity.

For the Trichosporon group, 6 different RFLP profiles characterized the 6 profiles recognized by biochemical methods. Sequencing of the D1/D2 domain confirmed 
Table 2. Molecular characteristics of yeast isolates

\begin{tabular}{|c|c|c|}
\hline API identification ${ }^{1}$ & Size of RFLP products, bp & $\begin{array}{l}\text { Identification by sequencing } \\
\text { of D1/D2 region }{ }^{2}\end{array}$ \\
\hline Candida famata & $190,250,270,500$ & Can. famata \\
\hline Candida krusei & $170,190,230,260,530$ & Can. krusei \\
\hline Candida parapsilosis & $190,260,390,500$ & Can. parapsilosis \\
\hline Candida catenulata & $160,180,220,280,410,490$ & Can. catenulata \\
\hline Candida rugosa & Not amplified & Can. rugosa \\
\hline Candida utilis & $150,190,320,490$ & Can. utilis \\
\hline Candida inconspicua & $160,190,220,450,500$ & Can. inconspicua \\
\hline Candida sake & $160,180,320,450,500$ & Can. sake \\
\hline Trichosporon mucoides & $270,320,600$ & T. mucoides \\
\hline Cryptococcus laurentii & $200,270,320,600$ & Trichosporon cutaneum \\
\hline Trichosporon asahii & 270,950 & Trichosporon aquatile \\
\hline Trichosporon inkin & $270,390,600$ & Trichosporon lactis \\
\hline Unacceptable profile & $220,270,320,650$ & Trichosporon gracile \\
\hline Cryptococcus curvatus & $230,320,530,590$ & Crypto. curvatus \\
\hline Cryptococcus uniguttulatus & $190,215,220,250,270,290,380$ & Filobasidium uniguttulatum \\
\hline Geotrichum candidum & $190,290,480,500$ & Galactomyces geotrichum \\
\hline Rhodotorula glutinis & $190,230,240,350,390,500$ & R. glutinis \\
\hline
\end{tabular}

${ }^{1}$ API system (bioMérieux, Marcy l'Etoile, France).

${ }^{2}$ Confirmatory identification by sequencing D1/D2 region of $26 \mathrm{~S}$ rRNA gene; D1/D2 sequencing confirmed the API identification at the species level, and homologies from 99 to $100 \%$ were obtained with sequences in GenBank.

the limited ability of the API ID 32C method to provide reliable identification of isolates of Trichosporon species, as previously reported (Colombo et al., 2011). Only Trichosporon mucoides and Crypto. curvatus were correctly identified by biochemical tests. All isolates belonging to the Trichosporon cutaneum, Trichosporon lactis, and Trichosporon aquatile species were misclassified as Crypto. laurentii, Trichosporon inkin, and Trichosporon asahii, respectively. Two isolates of Trichosporon gracile could not be identified.

Dendrogram analysis of RFLP fragments was carried out using the unweighted pair-group method with arithmetic mean algorithm and Dice similarity coefficient, and a database of yeast 18S-ITS1-5.8S RFLP patterns was constructed. Figure 1 shows the RFLPbased dendrogram with several strains of each species identified. Each strain of the same species showed similar digestion profiles with 90 to $100 \%$ similarity coefficients.

\section{DISCUSSION}

Commercial yeast identification methods based on morphological and physiological characteristics were designed to shorten the identification time of yeast isolates in the clinical laboratory, but their use for identification of environmental and wild yeasts is often inconclusive. The use of these systems, as well as geographical variations, could explain the discrepancy in the distribution of species reported in several surveys regarding yeasts isolated from bovine mastitic milk. Candida, Pichia, Cryptococcus, and Rhodotorula were the most frequent genera isolated from milk of cows with mastitis in southern Brazil (Spanamberg et al. 2008), whereas the genera Candida, Trichosporon, Cryptococcus, and Saccharomyces were isolated from subclinical mastitic cows in Turkey (Türkyilmaz and Kaynarca, 2010). Bourtzi-Hatzopoulou et al. (2003) also reported that the yeasts isolated as a causative agent of bovine mastitis in Greece belonged to the Candida, Geotrichum, and Rhodotorula genera. Moreover, the distribution of yeast species is diverse in surveys from different countries (Seker, 2010; Türkyilmaz and Kaynarca, 2010; Segundo Zaragoza et al., 2011), and only few data, to our knowledge, are reported for Italy (Moretti et al., 1998; Scaccabarozzi et al., 2011).

Progress in molecular biology has provided a large number of DNA-based techniques for identifying and characterizing environmental yeast isolates. Restriction enzyme analysis of the 18S rDNA gene was used for identifying yeast strains associated with several beverages (Dlauchy et al. 1999). Recently, RFLP analysis of the $5.8 \mathrm{~S}$ rRNA gene and the 2 ribosomal ITS has been successfully used to detect and differentiate several yeast species in both clinical and wild environmental strains (Carvalho et al., 2010; Diba et al., 2012). Previous works (Guillamón et al., 1998; Esteve-Zarzoso et al., 1999) suggested the value of using a database containing endonuclease restriction patterns for the 5.8-ITS region for the identification of environmental or wild yeast strains. To our knowledge, this is the first report of PCR-RFLP analysis of 18S-ITS1-5.8S rDNA region digested with the single enzyme HaeIII as a rapid and relatively inexpensive molecular procedure for accurate differentiation of most yeast species isolated in bovine mastitic milk samples. 


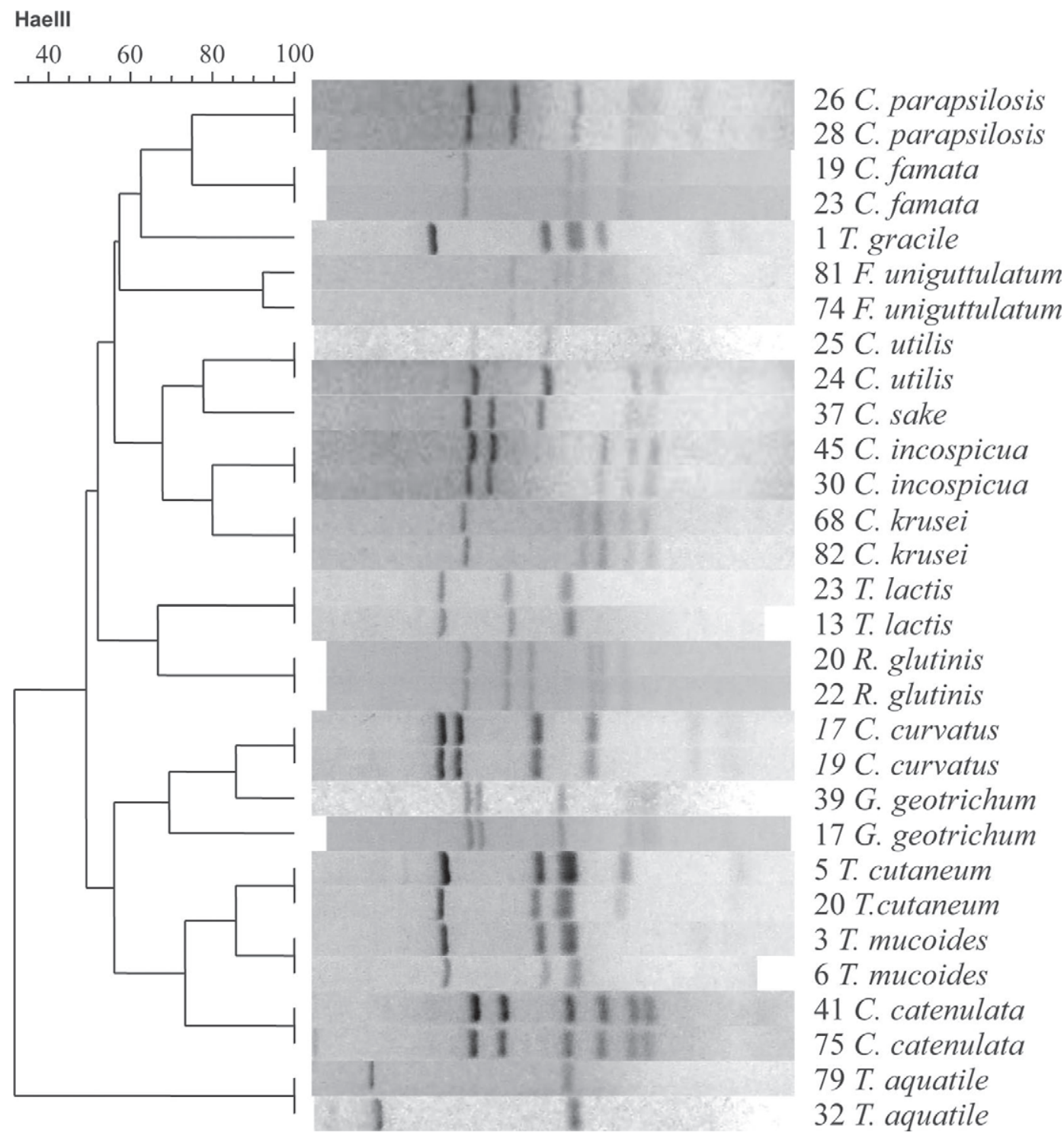

Figure 1. Dendrogram of representative PCR-RFLP patterns from each yeast species identified: Candida parapsilosis, Candida famata, Trichosporon gracile, Filobasidium uniguttulatum, Candida utilis, Candida sake, Candida inconspicua, Candida krusei, Trichosporon lactis, Rhodotorula glutinis, Cryptococcus uniguttulatus, Geotrichum candidum, Trichosporon cutaneum, Trichosporon mucoides, Candida catenulata, and Trichosporon aquatile.

In our study, the combined phenotypic and molecular approach enabled identification of 17 yeast species belonging to the genera Candida (47.9\%), Cryptococcus (21.1\%), Trichosporon (19.7\%), Geotrichum (7.1\%), and Rhodotorula $(4.2 \%)$.

Candida famata (teleomorph Debaryomyces hansenii) was the predominant species, and the majority of strains (88.9\%) were isolated from Sardinian milk samples, confirming that this species is an important component of the microflora of both Sardinian ovine and bovine milk (Cosentino et al., 2001; Fadda et al., 2004). Interestingly, Candida albicans was not observed among the species of the prevalent genus, in agree- ment with recent studies in Turkey (Türkyilmaz and Kaynarca, 2010; Seker, 2010) and Brazil (Spanamberg et al., 2008), although its presence has been reported in other surveys (de Casia dos Santos and Marin, 2005; Segundo Zaragoza et al., 2011).

A limitation of our method was that Can. rugosa could not be amplified by the set of primers used, presumably because of a limitation of the forward NS1 primer, as reported by Mannarelli and Kurtzman (1998).

In regard to the genera Cryptococcus and Trichosporon, the RFLP technique used in this study gave characteristic restriction profiles for each species, and sequencing of the D1/D2 region allowed not only suc- 
cessful identification of Trichosporon gracile (which API ID 32C could not), but also the correction of misidentified isolates. Cryptococcus curvatus and Crypto. uniguttulatus (sequence in GenBank is reported as teleomorph $F$. uniguttulatum) were successfully identified with both phenotypic and molecular methods, whereas identification of Crypto. laurentii strains at an excellent level by the API system was corrected to Trichosporon cutaneum by sequencing. According to the data reported in this and previous studies, it is evident that morphological and biochemical methods are not sufficient for Trichosporon species identification (Ahmad et al., 2005; Rodriguez-Tudela et al., 2005). The API ID $32 \mathrm{C}$ system is programmed to identify only 3 species of Trichosporon: T. asahii, T. inkin, and T. mucoides; consequently, it was unable to identify $T$. cutaneum, T. lactis, T. aquatile, and T. gracile species in the milk samples analyzed.

\section{CONCLUSIONS}

The 18S-ITS1-5.8S region appears to be useful in detecting genetic variability among yeast species, which is valuable for taxonomic identification to the species level. We have established a RFLP database for yeast species identified in milk samples using the software GelCompar II, creating an initial method for veterinary yeast identification. Once the database of species has been enlarged, rapid and reliable identification of yeast species from milk will be possible.

\section{ACKNOWLEDGMENTS}

The authors thank Germano Orrù (DNA Sequencing Service, AOU-Cagliari, Department of Surgical Sciences, University of Cagliari, Italy) for his valuable support and Patrick L. McDonough (College of Veterinary Medicine, Cornell University, Ithaca, NY) for advice.

\section{REFERENCES}

Ahmad, S., M. Al-Mahmeed, and Z. U. Khan. 2005. Characterization of Trichosporon species isolated from clinical specimens in Kuwait. J. Med. Microbiol. 54:639-646.

Bourtzi-Hatzopoulou, E., A. Zdragas, E. Petridou, and G. Filiousis. 2003. Yeasts as a causative agent of bovine mastitis in Greece. J. Hellenic Vet. Med. Soc. 54:105-110.

Carvalho, C. M., S. Meirinho, M. L. F. Estevinho, and A. Choupina. 2010. Yeast species associated with honey: Different identification methods. Arch. Zootech. 59:103-113.

Chahota, R., R. Katoch, A. Mahajan, and S. Verma. 2001. Clinical bovine mastitis caused by Geotrichum candidum. Vet. Archiv. 71:197-201.

Colombo, A. L., A. C. B. Padovan, and G. M. Chaves. 2011. Current knowledge of Trichosporon spp. and trichosporonosis. Clin. Microbiol. Rev. 24:682-700.

Cosentino, S., M. E. Fadda, M. Deplano, A. F. Mulargia, and F. Palmas. 2001. Yeasts associated with Sardinian ewe's dairy products. Int. J. Food Microbiol. 69:53-58. de Casia dos Santos, R., and J. M. Marin. 2005. Isolation of Candida spp. from mastitic bovine milk in Brazil. Mycopathologia 159:251-253.

Diba, K., A. Namaki, H. Ayatolahi, and H. Hanifian. 2012. Rapid identification of drug resistant Candida species causing recurrent vulvovaginal candidiasis. Med. Mycol. J. 53:193-198.

Dlauchy, D., J. Tornai-Lehoczki, and G. Péter. 1999. Restriction enzyme analysis of PCR amplified rDNA as a taxonomic tool in yeast identification. Syst. Appl. Microbiol. 22:445-453.

Esteve-Zarzoso, B., C. Belloch, F. Uruburu, and A. Querol. 1999. Identification of yeasts by RFLP analysis of the $5.8 \mathrm{~S}$ rRNA gene and the two ribosomal internal transcribed spacers. Int. J. Syst. Bacteriol. 49:329-337.

Fadda, M. E., V. Mossa, M. B. Pisano, M. Deplano, and S. Cosentino. 2004. Occurrence and characterization of yeasts isolated from artisanal Fiore Sardo cheese. Int. J. Food Microbiol. 95:51-59.

Fadda, M. E., S. Viale, M. Deplano, M. B. Pisano, and S. Cosentino. 2010. Characterization of yeast population and molecular fingerprinting of Candida zeylanoides isolated from goat's milk collected in Sardinia. Int. J. Food Microbiol. 136:376-380.

Guillamón, J. M., J. Sabaté, E. Barrio, J. Cano, and A. Querol. 1998. Rapid identification of wine yeast species based on RFLP analysis of the ribosomal internal transcribed spacer (ITS) region. Arch. Microbiol. 169:387-392.

Kurtzman, C. P., and J. F. Fell. 2000. The Yeast: A Taxonomic Study. Elsevier, Amsterdam, the Netherlands.

Mannarelli, B. M., and C. P. Kurtzman. 1998. Rapid identification of Candida albicans and other human pathogenic yeasts by using short oligonucleotides in a PCR. J. Clin. Microbiol. 36:1634-1641.

Möller, A., U. Truyen, and U. Roesler. 2007. Prototheca zopfii genotype 2: The causative agent of bovine protothecal mastitis? Vet. Microbiol. 120:370-374.

Moretti, A., P. Pasquali, G. Mencaroni, L. Boncio, and D. Piergili Fioretti. 1998. Relationship between cell counts in bovine milk and the presence of mastitis pathogens (yeasts and bacteria). Zentralbl. Veterinarmed. B 45:129-132.

Odds, F. C., M. G. Rinaldi, C. L. Cooper, A. Fothergill, L. Pasarell, and M. R. McGinnis. 1997. Candida and Torulopsis: A blinded evaluation of use of pseudohypha formation as basis for identification of medically important yeasts. J. Clin. Microbiol. 35:313-316.

Rodriguez-Tudela, J. L., T. M. Diaz-Guerra, E. Mellado, V. Cano, C. Tapia, A. Perkins, A. Gomez-Lopez, L. Rodero, and M. Cuenca-Estrella. 2005. Susceptibility patterns and molecular identification of Trichosporon species. Antimicrob. Agents Chemother. 49:4026-4034.

Scaccabarozzi, L., C. Locatelli, G. Pisoni, G. Manarolla, A. Casula, V. Bronzo, and P. Moroni. 2011. Short communication: Epidemiology and genotyping of Candida rugosa strains responsible for persistent intramammary infections in dairy cows. J. Dairy Sci. 94:4574-4577.

Schukken, Y. H., J. Hertl, D. Bar, G. J. Bennett, R. N. González, B. J. Rauch, C. Santisteban, H. F. Schulte, L. Tauer, F. L. Welcome, and Y. T. Gröhn. 2009. Effects of repeated gram-positive and gram-negative clinical mastitis episodes on milk yield loss in Holstein dairy cows. J. Dairy Sci. 92:3091-3105.

Segundo Zaragoza, C., R. A. Cervantes Olivares, A. E. Ducoing Watty, A. de la Pèna Moctezuma, and L. Villa Tanaca. 2011. Yeasts isolation from bovine mammary glands under different mastitis status in the Mexican High Plateu. Rev. Iberoam. Micol. 28:79-82.

Seker, E. 2010. Identification of Candida species isolated from bovine mastitic milk and their in vitro hemolytic activity in Western Turkey. Mycopathologia 169:303-308.

Spanamberg, A., E. A. Wünder, D. I. Brayer Pereira, J. Argenta, E. M. Cavallini Sanches, P. Valente, and L. Laerte Ferreiro. 2008. Diversity of yeasts from bovine mastitis in Southern Brazil. Rev. Iberoam. Micol. 25:154-156.

Türkyilmaz, S., and S. Kaynarca. 2010. The slime production by yeasts isolated from subclinical mastitic cows. Acta Vet. (Brno) 79:581-586. 